\title{
Expression and purification of recombinant NFI proteins for functional analysis
}

\author{
Gabriel Kollárovič ${ }^{1}$, Dušana Majera ${ }^{1,2}$, Katarína Luciaková ${ }^{1}$ and Peter Baráth ${ }^{1}$ \\ ${ }^{1}$ Laboratory of Molecular Biology, Cancer Research Institute, Slovak Academy of Sciences, Vlárska 7, 83391 Bratislava, \\ Slovakia; E-mail: gabriel.kollarovic@savba.sk \\ 2 Department of Biochemistry and Molecular and Structural Biology, Jozef Stefan Institute, Jamova 39, SI-1000 Ljubljana, \\ Slovenia
}

\begin{abstract}
Nuclear factor I (NFI) is a transcription factor playing wide role in signal transduction pathways and developmental processes in higher eukaryotes. In order to produce recombinant NFI proteins for functional and structural studies, full length cDNAs of individual isoforms were subcloned into pETM30 vector and expressed in Escherichia coli. Although the fusion proteins containing both glutathione S-transferase (GST) and $\mathrm{His}_{6}$ tags at the $\mathrm{N}$-terminus could be overexpressed in detectable amounts, they were found mainly, if not exclusively, in insoluble form. Purification yield was improved by modification of cell disruption procedure and by the use of detergent Tween 20 . The final purification strategy represents a triple affinity chromatography consisting of prepurification of bacterial lysate on Heparin-Sepharose with subsequent immobilized metal affinity and glutathione affinity chromatography. Heparin chromatography was crucial for obtaining active NFI proteins, whereas the other steps significantly improved the purity of isolated proteins. As demonstrated by EMSA and DNase I protection assay, the recombinant proteins were able to recognize their cognate DNA sequences.
\end{abstract}

Key words: Nuclear factor I — Affinity chromatography — Soluble protein production

\section{Introduction}

Adenine nucleotide translocators (ANTs) belong to a large family of mitochondrial membrane carriers (Fiore et al. 1998). ANTs catalyze the exchange of mitochondrial ATP for cytosolic ADP, thus playing an important role in sensing the mitochondria/cytosolic energetic gradient. Translocators have also been implicated in apoptotic processes through their involvement in mitochondrial permeability transition pore (Halestrap and Brenner 2003). Human ANTs are encoded by four genes: ANT1, ANT2, ANT3 and ANT4 (Fiore et al. 1998; Dolce et al. 2005). The ANT2 isoform is unique as its expression is tightly regulated by the growth and differentiation status (Barath et al. 1999a). We recently described a unique role for the transcription factor - nuclear factor I (NFI) as an

Correspondence to: Gabriel Kollárovič, Laboratory of Molecular Biology, Cancer Research Institute, Slovak Academy of Sciences, Vlárska 7, 83391 Bratislava, Slovakia

E-mail: gabriel.kollarovic@savba.sk active repressor of ANT2 in growth-arrested cells (Luciakova et al. 2003, 2008). NFI was initially discovered as a protein in uninfected human HeLa cells required for replication of adenoviral DNA (Nagata et al. 1982). Later data indicated that the same protein was involved in transcriptional regulation of many cellular genes (Jones et al. 1987). In addition, NFI has been implicated in growth and developmental processes through the recognition of gene promoters regulated by signal transduction pathways (reviewed by Gronostajski 2000).

In vertebrates, NFI proteins are encoded by four isogenes ( $n f i-a, n f i-b, n f i-c, n f i-x)$ and exist in multiple splice variants. In C. elegans and Drosophila, $n f i$ gene is present in a single copy and no $n f i$ genes were found in unicellular organisms. The NFIs recognize palindrome consensus sequence 5 '-TTGGC(N5)GCCAA-3' and interact with the DNA as a dimer, either homo- or heterodimer. NFI can also bind specifically to individual half sites but with reduced affinity as compared to the palindrome consensus sequence (Meisterernst et al. 1988). NFI proteins bind DNA through conserved N-terminal domain. Recent data show that the 
N-terminal domain of NFIs shares functional and structural homology with the MH1 domain of Smad proteins containing similar conservative Cys-His motif with zinc binding potential (Sadreyev and Grishin 2003; Stefancsik and Sarkar 2003). The C-terminal part contains effector domains and exhibits high degree of variability due to low sequence homology and alternative splicing (Gronostajski 2000). It has been shown that the individual NFI isoforms can activate or repress transcription of genes depending on promoter and cellular context. For example, NFI-A1 and NFI-B2 are activators, whereas NFI$\mathrm{C} 2$ and NFI-X2 are repressors of $\alpha$-sarcoglycan gene in myoblasts. Alternatively, all of them act as activators in myotubes, with NFI-C2 the least potent (Delgado-Olguín et al. 2004). Posttranslational modifications of NFI proteins can further modulate their function. So far, phosphorylation (Cooke and Lane 1999; Nilsson et al. 2006; Sawada and Yamaguchi 2006) and glycosylation (Kane et al. 2002; Mukhopadhyay and Rosen 2007) were detected, which affected DNA binding affinity or the ability of NFIs to interact with other proteins.

Disruption studies have revealed that NFI transcription factors are essential for proper embryonic development. Knockdown of NFI-A expression by siRNA prevented the expression of the markers of gliogenesis in chick central nervous system (Deneen et al. 2006). Other studies performed in mice deficient in individual NFI isoforms found NFI-B as important factor for lung maturation (Steele-Perkins et al. 2005), while NFI-C was essential for teeth differentiation (Park et al. 2007) and NFI-X was crucial for normal brain development (Campbell et al. 2008). Different phenotypes of NFI knockouts can not be fully explained by tissue specific expression of individual isoforms (Chaudhry et al. 1997). More likely, transcriptional regulation is achieved through interactions of individual NFI with different protein partners.

So far, isolation of soluble full length and intact NFI proteins for functional and proteomic studies has not been published. In the present study we report bacterial expression and purification of recombinant full length NFI proteins. We expressed all four NFI isoforms (-A, $-\mathrm{B},-\mathrm{C}$ and $-\mathrm{X})$ as fusion proteins with $\mathrm{N}$-terminal $\mathrm{His}_{6}{ }^{-}$and glutathione S-transferase (GST)-tags. We also produced antibodies recognizing NFI proteins for immunodetection and immunoprecipitation. The protocol described in this paper is prerequisite for identification of NFI partner proteins from mammalian cellular and/or nuclear extracts. This information will help to dissect the role of NFI in signal transduction pathways and developmental processes.

\section{Materials and Methods}

Plasmids

cDNAs encoding NFI-A1, -B2, -C2 and -X1 were kindly provided by Dr. M. Imagawa (Graduate School of Pharma- ceutical Sciences, Nagoya City University, Nagoya, Japan). The coding region of individual NFIs was recloned into the expression vector pETM30 (EMBL, Heidelberg, Germany). To obtain the NFI-B2 DNA binding domain (DBD) construct, NcoI/KpnI fragment from pETM30 vector was cloned into pETM11 vector using the NcoI and KpnI restriction sites.

\section{Expression of recombinant NFIs}

To express recombinant NFI proteins, bacterial strain BL21 Rosetta (DE3) pLysS containing the corresponding vectors was grown in LB medium supplemented with kanamycin $(25 \mu \mathrm{g} / \mathrm{ml})$ at $37^{\circ} \mathrm{C}$ until $\mathrm{OD}_{600}$ reached 1.0. Expression of proteins was induced by addition of $0.1 \mathrm{mmol} / \mathrm{dm}^{3} \mathrm{IPTG}$ and carried out for $3 \mathrm{~h}$ at $25^{\circ} \mathrm{C}$. Cells were harvested by centrifugation and stored at $-20^{\circ} \mathrm{C}$. To produce $\mathrm{His}_{6}$ tagged NFI-B2 $\mathrm{DBD}$ protein in form of inclusion bodies, the expression was carried out overnight at $37^{\circ} \mathrm{C}$.

Alternatively, recombinant NFI proteins were produced in autoinducing medium. The bacterial cultures were grown to saturation $\left(\mathrm{OD}_{600} \cong 6\right)$ overnight at $30^{\circ} \mathrm{C}$ in ZYM-5052 media (Studier 2005). Cells were harvested and stored at $-20^{\circ} \mathrm{C}$.

\section{Purification of NFI-B2 DBD}

Pelleted bacteria containing expressed NFI-B2 DBD were resuspended in $\mathrm{PBS}$ with $5 \mathrm{mmol} / \mathrm{dm}^{3} \mathrm{MgCl}_{2}, 1 \mathrm{U} / \mathrm{ml}$ DNase, $1 \mathrm{mg} / \mathrm{ml}$ lysosyme and incubated on ice for $20-30$ min. Cells were intensively sonicated and centrifuged. Pellet was resuspended in $50 \mathrm{mmol} / \mathrm{dm}^{3}$ Tris- $\mathrm{HCl}(\mathrm{pH}$ 8.0), $1 \mathrm{mmol} / \mathrm{dm}^{3}$ EDTA, $100 \mathrm{mmol} / \mathrm{dm}^{3} \mathrm{NaCl}, 1 \mathrm{mg} / \mathrm{ml}$ lysosyme and incubated $20 \mathrm{~min}$ at $37^{\circ} \mathrm{C}$. $\mathrm{MgCl}_{2}$ to $5 \mathrm{mmol} /$ $\mathrm{dm}^{3}$ and DNase to $1 \mathrm{U} / \mathrm{ml}$ were added and incubated for additional $5 \mathrm{~min}$ at $37^{\circ} \mathrm{C}$. Cell suspension was sonicated and $\mathrm{NaCl}$ and TritonX-100 were added to final concentrations of $1 \mathrm{~mol} / \mathrm{dm}^{3}$ and $1 \%$, respectively. After centrifugation (15 min at $7800 \times g$ ) the pellet containing inclusion bodies was resuspended in a minimal volume of sterile water. Inclusion bodies were solubilized in buffer $\mathrm{U}$ (PBS, $8 \mathrm{~mol} / \mathrm{dm}^{3}$ urea) and incubated overnight at $4^{\circ} \mathrm{C}$. Insoluble particles were separated by centrifugation as before. Soluble fraction was supplemented with $10 \mathrm{mmol} / \mathrm{dm}^{3}$ imidazole and $5 \mathrm{mmol} /$ $\mathrm{dm}^{3} \beta$-mercaptoethanol. The sample was applied on $\mathrm{Ni}^{2+}$ HiTrap Chelating column (GE Healthcare), washed with $10 \mathrm{mmol} / \mathrm{dm}^{3}$ imidazole in buffer $\mathrm{U}$ and eluted with 300 $\mathrm{mmol} / \mathrm{dm}^{3}$ imidazole in buffer U. Fractions containing the target protein were pooled, diluted twice with $8 \mathrm{~mol} / \mathrm{dm}^{3}$ urea and applied on SP-Sepharose column. Protein was eluted with linear $\mathrm{NaCl}$ gradient (0 to $400 \mathrm{mmol} / \mathrm{dm}^{3} \mathrm{NaCl}$ in $20 \mathrm{mmol} / \mathrm{dm}^{3}$ sodium phosphate ( $\mathrm{pH} 7.4$ ) and $8 \mathrm{~mol} / \mathrm{dm}^{3}$ urea). Collected fractions were tested for the presence of 
recombinant protein by SDS-PAGE. Three fractions with the highest protein concentration were pooled and dialysed against water overnight at $4^{\circ} \mathrm{C}$. Precipitated sample was stored at $-20^{\circ} \mathrm{C}$ for immunization purposes.

\section{Preparation of NFI antibodies}

Rabbit was intramuscularly immunized with suspension of purified NFI-B2 DBD $\left(0.7 \mathrm{mg}\right.$ of protein in $\left.1 \mathrm{ml} \mathrm{H} \mathrm{H}_{2} \mathrm{O}\right)$ mixed with complete Freund's adjuvant. On days 22 and 31 the immunization was repeated as before with NFI-B2 DBD in incomplete Freund's adjuvant. Immune serum was collected on day 41 and stored at $-20^{\circ} \mathrm{C}$.

Immunoglobuline ( $\operatorname{IgG}$ ) was isolated from immune serum according to the manufacturer's instructions using HiTrap Protein-A Sepharose column (GE Healthcare). Samples eluted with $0.1 \mathrm{~mol} / \mathrm{dm}^{3}$ citric acid of $\mathrm{pH} 3.5$ were immediately neutralized by addition of $\mathrm{Na}_{2} \mathrm{HPO}_{3}$ to final $\mathrm{pH}$ 7.4. Fractions with the highest IgG concentration were pooled, supplemented with $0.01 \%$ sodium azide and stored at $4^{\circ} \mathrm{C}$.

\section{Purification of recombinant NFI proteins}

Pelleted bacterial cells were resuspended in PBS containing $5 \mathrm{mmol} / \mathrm{dm}^{3} \mathrm{MgCl}_{2}, 1 \mathrm{U} / \mathrm{ml}$ DNase, $1 \mathrm{mg} / \mathrm{ml}$ lysosyme, $0.02 \%$ Tween 20 and supplemented with protease inhibitors $\left(0.1 \mathrm{mmol} / \mathrm{dm}^{3}\right.$ PMSF, $1 \mu \mathrm{g} / \mu \mathrm{l}$ pepstatin, $1 \mu \mathrm{g} / \mu \mathrm{l}$ leupeptin $)$ and with $1 \mathrm{mmol} / \mathrm{dm}^{3} \beta$-mercaptoethanol. When testing alternative disruption protocols, individual components were modified (for details see Results). Cells were disrupted by sonication, centrifuged and the supernatant was applied on Heparin-Sepharose. The column was washed with binding buffer (PBS with $0.02 \%$ Tween $20,1 \mathrm{mmol} / \mathrm{dm}^{3} \beta$-mercaptoethanol and protease inhibitors as before) and the proteins were eluted stepwise with $0.25 \mathrm{~mol} / \mathrm{dm}^{3}$ and $0.55 \mathrm{~mol} / \mathrm{dm}^{3}$ $\mathrm{NaCl}$ in the binding buffer. The two fractions $(\mathrm{E} 1, \mathrm{E} 2)$ were individually applied to Ni-Sepharose resin. The column was washed with binding buffer containing $10 \mathrm{mmol} / \mathrm{dm}^{3}$ imidazole and the recombinant protein was eluted with PBS containing $0.02 \%$ Tween 20 and $0.2 \mathrm{~mol} / \mathrm{dm}^{3}$ imidazole.

Protein samples (soluble fraction from cell lysate, NiSepharose fractions or heparine fractions E1 or E2) were transferred onto Glutathione-Sepharose resin (Amersham) and washed with the binding buffer. The target protein was eluted with PBS containing $0.02 \%$ Tween 20 and reduced glutathione $\left(10 \mathrm{mmol} / \mathrm{dm}^{3}, \mathrm{pH} 8.0\right)$.

\section{SDS-PAGE and Western blot analysis}

Protein samples were separated by $4 \%$ stacking/10\% separating slab gel as described by Laemmli (1970). After electrophoresis, the gels were either stained with Commassie
Blue staining (CBB)-R250 or electroblotted onto Hybond ECL membrane (Amersham Biosciences). Membranes were incubated with diluted NFI immune serum $(1: 500)$ and developed with SuperSignalWest Pico chemiluminescent substrate (Pierce).

\section{Electrophoretic Mobility Shift Assay (EMSA)}

EMSA was performed according to Luciakova et al. (2003). Briefly, tested protein samples (approx. $10 \mathrm{ng}$ of purified recombinant NFI) were incubated with radiolabeled $\left({ }^{32} \mathrm{P}\right)$ double stranded DNA oligonucleotide NFI WT (5' TTTTGGATTGAAGCCAATATGATA- $\left.3^{\prime}\right)$. In the case of supershift experiment, $2 \mu$ g of purified $\operatorname{IgG}$ (see above) were added to the reaction mixture. Protein-DNA complexes were separated by native electrophoresis in Tris-borate buffer. Gels were dried and subjected to autoradiography and/or phosphoimaging using Typhoon Scanner (GE Healthcare).

\section{DNase I protection assay}

End- ${ }^{32}$ P-labeled DNA promoter fragment was amplified by PCR using plasmid pCAT ANT2 -542/-235 as a template. The assay was performed according to Barath et al. (1999b). $50 \mathrm{ng}$ of recombinant NFI protein was used in a single reaction mixture. Partly digested probe by DNase I was analysed by denaturing sequencing gel and visualized by phosphoimaging and/or autoradiography.

\section{Results}

Recombinant NFI proteins (NFI-A1, -B2, -C2, and -X1) were created by subcloning the individual rat cDNAs into the pETM30 vector. The N-terminus of the target protein was fused with double affinity tag ( His $_{6}$ and GST) separated by cleavage site for TEV protease. After IPTG induction and cell disruption, the soluble and insoluble protein fractions were analyzed by SDS-PAGE. Molecular masses of expressed recombinant proteins corresponded to the expected values (86 kDa for GST-NFI-A1, $86 \mathrm{kDa}$ for GST-NFI-B2, 80 $\mathrm{kDa}$ for GST-NFI-C2 and $79 \mathrm{kDa}$ for GST-NFI-X1), but the proteins were found in insoluble fractions (Fig. 1, left upper panel). In order to improve solubility, alternative protocol for protein induction was tested. The autoinducing medium ZYM-5052 contains 0.2\% lactose and 0.05\% glucose which allows gradual switch from glucose to lactose metabolism during the bacterial growth (Studier 2005). The onset of lactose utilization is accompanied with expression of recombinant protein, which often leads to production of soluble proteins. In spite of the slower protein production, recombinant NFI proteins were again found in insoluble form (Fig. 1, right upper panel). 

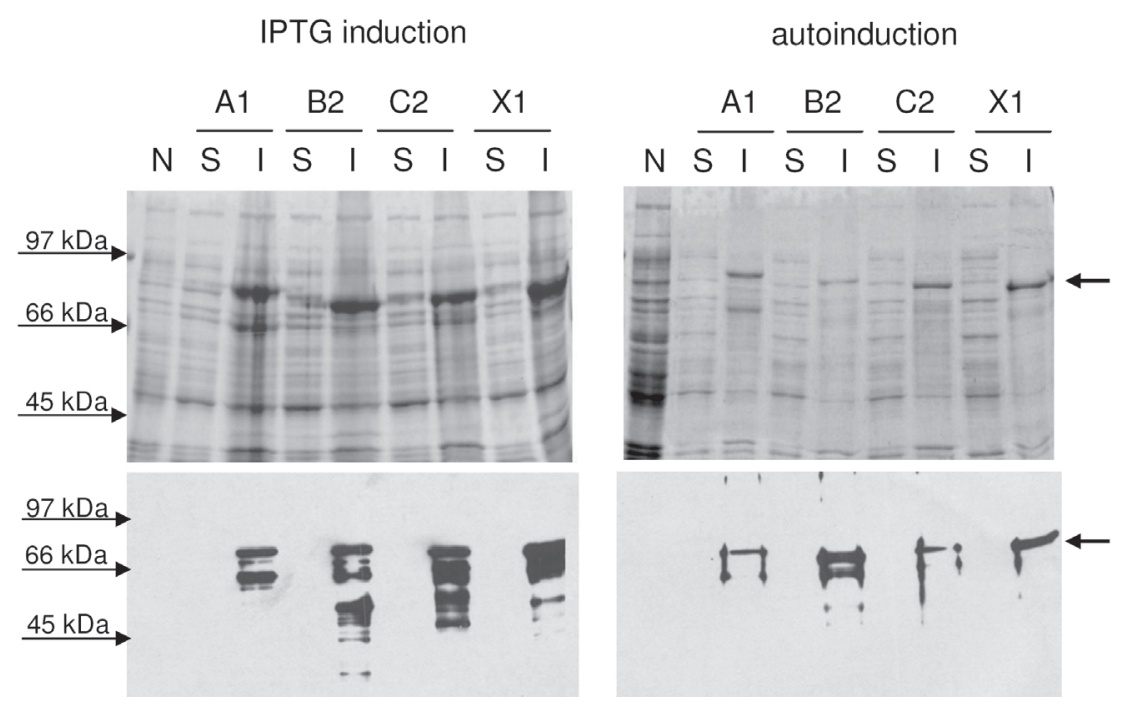

Figure 1. SDS-PAGE and Western blot analysis of the protein samples from bacteria overexpressing NFI-A1, -B2, -C2, and -X1. Expression of GST and $\mathrm{His}_{6}$ tagged fusion proteins was induced either by IPTG (left panels) or by autoinduction medium (right panels). The upper panels represent CBB stained SDS-PAGE gels, whereas the lower panels show the Western blot analysis using NFI-B2 DBD immune serum prepared in this paper. Bacteria were disrupted by sonication and soluble (S) and insoluble (I) material was separated by centrifugation. Lane $\mathrm{N}$ represents noninduced fraction. Arrows represent expected molecular mass of NFI fusion proteins.

Cultivation temperature during protein production is a well described factor influencing solubility of the target protein. We tested decreased temperatures (down to $16^{\circ} \mathrm{C}$ ) in both IPTG and lactose driven induction protocols with no success in obtaining soluble recombinant protein. In parallel to our bacterial expression trials, we also tested NFI expression in yeast Pichia pastoris but failed to produce soluble protein (data not shown).

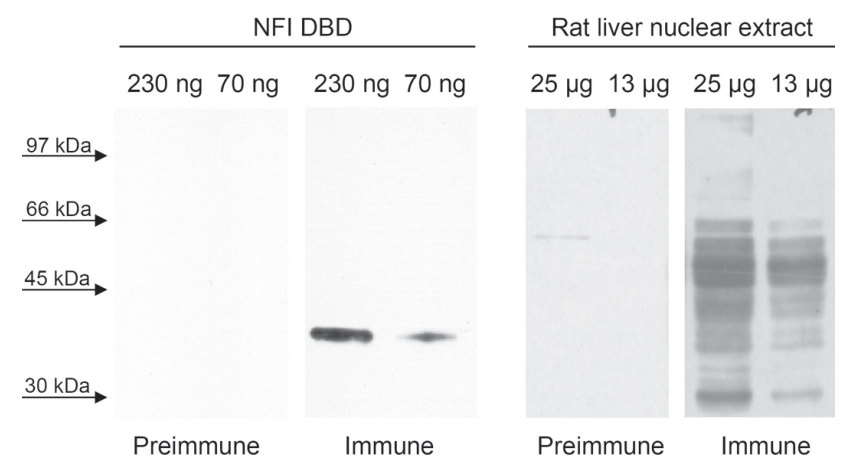

Figure 2. Specificity of NFI immune serum. Protein used in the immunization process and rat liver nuclear extract were separated by SDS-PAGE, transferred to nitrocellulose membrane and detected either by preimmune, or immune rabbit serum. The signals are clearly present after detection by immune serum only. Multiform appearance of NFI from rat liver nuclear extract is in agreement with its nature (sizes from 30 to $70 \mathrm{kDa}$ ) and our previous observations (Luciakova et al. 2003).
However, we used expressed DBD of NFI-B2 to produce general NFI antibodies. The protein in form of inclusion bodies was solubilized and purified under denaturing conditions using Ni-Sepharose and SP-Sepharose. Specificity of immune serum was confirmed by Western blot using purified antigen and mammalian nuclear extracts (Fig. 2). The DBD is the most conserved part of NFI proteins, therefore the antibodies recognize all four isoforms with similar affinities (Fig. 1, lower panels). Western blot analysis also confirmed the insolubility of expressed recombinant proteins from the previous experiments (Fig. 1).

Protein aggregation often results from hydrophobic interactions which may be decreased in the presence of detergents. For GST fusion proteins, a combination of N-lauryl-sarcosine with Triton-X100 has been shown to improve solubility of the target proteins (Frangioni and Neel 1993). At the same time, presence of detergents supports disruption of host cells which results in higher amount of starting material for protein purification.

Bacteria expressing NFI-A1 were sonicated in the presence of N-lauryl-sarcosine followed by the addition of TritonX100. The lysate was further purified either on Ni-Sepharose or Glutathione-Sepharose resins. Fractions eluted from the Ni-Sepharose column contained recombinant NFI-A1. On the other hand, we could not detect any protein eluted from Glutathione-Sepharose (Fig. 3). GST tag was not recognized even when purified NFI-A1 from Ni-Sepharose was applied to glutathione resin (data not shown). These observations sug- 
gest that extraction of expressed NFI protein in the presence of detergents used in this experiment results in higher protein solubility but the protein may not be folded properly.

Attempts to purify recombinant and soluble NFI proteins by the simple use of affinity tags were not successful. On the other hand, endogenous NFI protein was previously isolated from mammalian nuclear extracts using immobilized heparin (Gao et al. 1996; Luciakova et al. 2003; Barath et al. 2004). Heparin is a well known ligand for DNA binding proteins, growth factors, coagulation protein synthesis factors and steroid receptors and is used especially for purification of low abundance proteins (Xiong et al. 2008). For purification of recombinant NFI we modified the following parameters of protein expression and purification scheme: i) for single protein preparation, an increased volume of bacterial culture (2 liters) induced by IPTG at $25^{\circ} \mathrm{C}$ was used; ii) cells were disrupted by combination of lysozyme treatment and sonication; iii) Tween 20 was present in all purification buffers. This mild detergent was originally used to solubilize membrane proteins during extraction process but was also described to prevent protein adsorption to column surfaces (Robinson et al. 2004). Bacterial lysate was applied to Heparin-Sepharose column and eluted in two subsequent steps with buffers containing $0.25 \mathrm{~mol} / \mathrm{dm}^{3}$ and $0.55 \mathrm{~mol} / \mathrm{dm}^{3} \mathrm{NaCl}$, respectively (Fig. 4A, lanes E1 and E2).

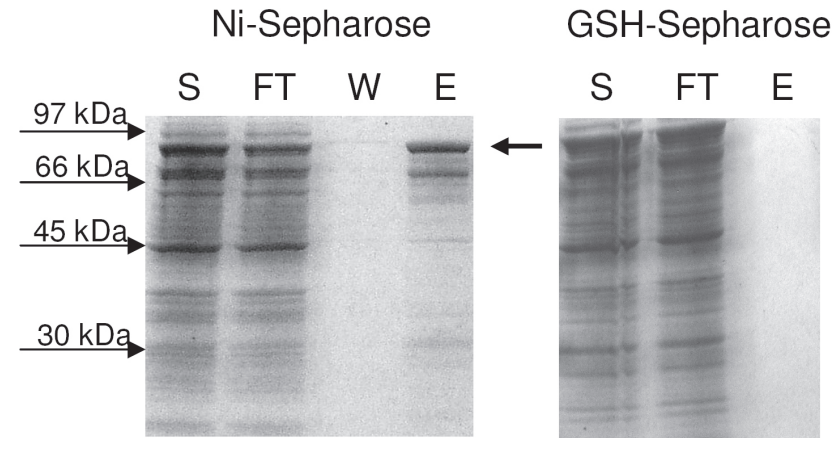

Figure 3. Extraction and purification of NFI-A1 in the presence of $\mathrm{N}$-lauryl-sarcosine. Cells were sonicated in the presence of N-laurylsarcosine. Unbound protein was washed out and the target protein was eluted by $200 \mathrm{mmol} / \mathrm{dm}^{3}$ imidazole (Ni-Sepharose column; left panel) or eluted by $10 \mathrm{mmol} / \mathrm{dm}^{3}$ reduced glutathione of $\mathrm{pH}$ 8.0 (Glutathione (GSH)-Sepharose column, right panel). S, protein sample applied on the column; FT, flow-through - unbound fraction; $\mathrm{W}$, fraction washed by binding buffer; E, eluted fraction. Arrow represents the predicted molecular mass of NFI-A1 fusion protein.

Each salt fraction was further purified on Ni-Sepharose and Glutathione-Sepharose columns. Purification progress was monitored by SDS-PAGE with CBB and immunodetection

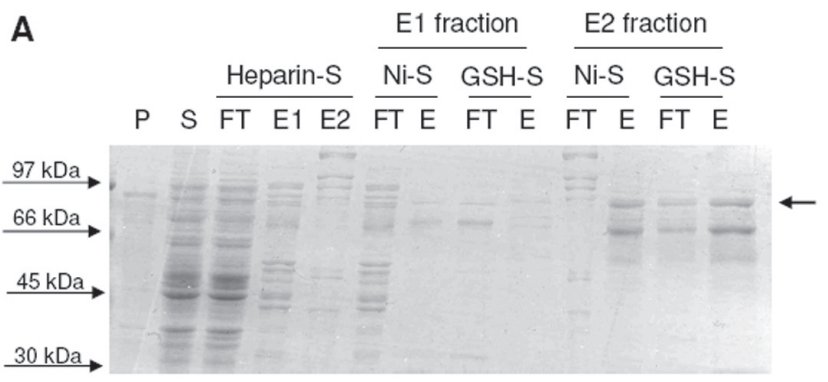

B

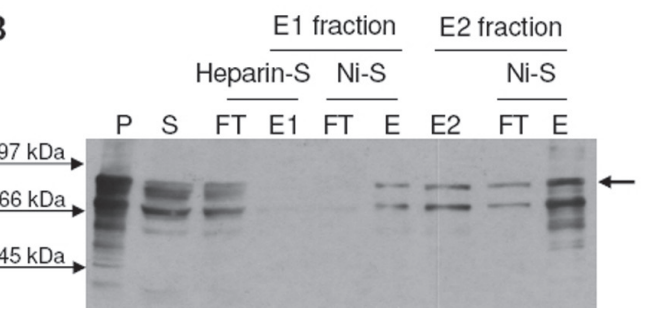

C

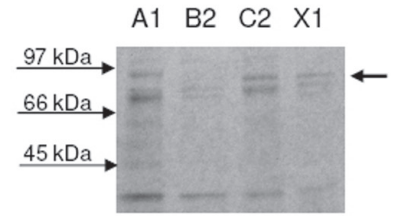

Figure 4. Purification of NFIs on Heparin-Sepharose, Ni-Sepharose or Glutathione-Sepharose column. A. Proteins from Heparin-Sepharose (Heparin-S) column were eluted by two step elution. E1, elution in low salt buffer (PBS supplemented by $0.25 \mathrm{~mol} / \mathrm{dm}^{3} \mathrm{NaCl}$ and $0.02 \%$ Tween 20 ); E2, elution in high salt buffer (PBS supplemented by $0.55 \mathrm{~mol} / \mathrm{dm}^{3} \mathrm{NaCl}$ and $0.02 \%$ Tween 20 ). Each salt fraction was further purified on NiSepharose (Ni-S) and Glutathione-Sepharose (GSH-S) columns; P, pellet - insoluble fraction; S, protein sample applied on the column; FT, flowthrough - unbound fraction; E, eluted fraction. Arrow represents the predicted molecular mass of the NFI-A1 fusion protein. B. Western blots of recombinant NFI-A1 purified on Heparin-S and Ni-S as in A, using NFI-B2 DBD antibody prepared in this paper. C. SDS-PAGE analysis of purified NFI-A1, -B2, -C2, -X1 fusion proteins. All of these proteins were purified on Heparin-S (high salt elution) and subsequently on Ni-S. Aliquots from Ni-S elution were analyzed by SDS-PAGE. Arrowheads represent the predicted molecular masses of the NFI fusion proteins. 
(Fig. 4A and B). The results show that even though the higher salt heparin fraction E2 contained less total protein, it was enriched in the recombinant NFI (Fig. 4A). Western blot analysis shows the presence of NFI protein also in the lower salt heparin fraction E1 but only after purification/concentration on Ni-Sepharose (Fig. 4B).

After successful purification of recombinant NFI-A1, we applied the described protocol to the remaining NFI isoforms (NFI-B2, -C2, and -X1). The samples eluted from the Ni-Sepharose were separated by SDS-PAGE and stained with CBB. Purified recombinant NFI proteins appeared in multiple forms (Fig. 4C). The size of the largest polypeptides

\section{A}

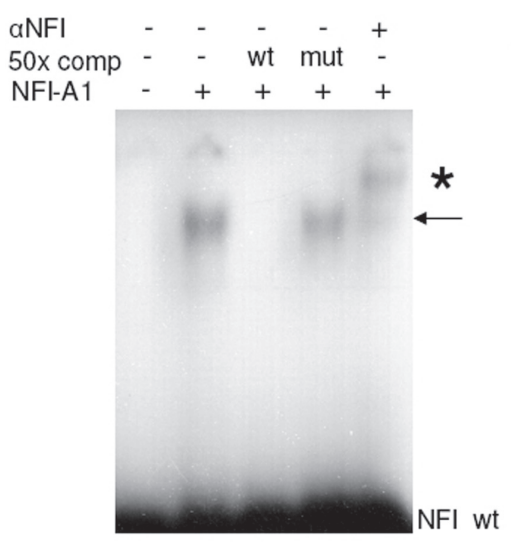

B

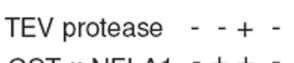

GST :: NFI-A1 - + + -

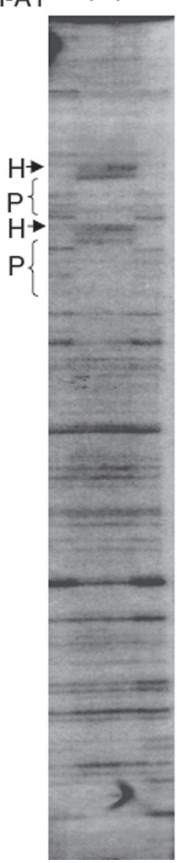

Figure 5. DNA binding properties of the purified NFI-A1 fusion protein. Protein sample was purified on Heparin-Sepharose (high salt fraction E2) and subsequently on Ni-Sepharose column. A. EMSA and supershift analysis was performed with $10 \mathrm{ng}$ of recombinant NFI-A1 and ${ }^{32} \mathrm{P}$ labeled probe containing a NFI bipartite consensus binding sequence (NFI wt). Wild type (wt) or mutated (mut) competitor unlabelled probe was added in 50-fold excess. Supershift was performed with $2 \mu \mathrm{g}$ of NFI-B2 DBD antibody prepared in this paper. Arrow represents the NFI-A1 specific shift, asterisk represents the supershifted protein. B. Binding of purified, recombinant NFI-A1 to promoter region of human ANT2 gene spanning the nucleotides -546/-235 was monitored by in vitro DNase I protection assay. Fusion protein, as well as NFI-A1 void of purification tags (cleaved off by TEV protease), were tested. Only the coding strand is shown. $\mathrm{H}$, hypersensitive sites; $\mathrm{P}$, protected area. corresponds to predicted molecular masses of the intact NFI isoforms. Shorter forms most likely result from the Cterminal truncation, since the purification tags crucial for the affinity purification are located at the N-terminus of the fusion proteins. Overall protein purification yield was very low ranging from 3 to $10 \mu \mathrm{g}$ of purified recombinant NFI protein from 1 litre of bacterial culture.

To test if purified NFI proteins had proper conformation and were not denaturated, we performed assays based on monitoring specific protein-DNA interactions. The recombinant protein purified on heparin and nickel columns recognized specific radiolabeled NFI oligonucleotide in EMSA (Fig. 5A, lane 2). The specificity of the interaction was further confirmed in competition experiment where the mutated probe failed to disrupt created protein-DNA complex (Fig. 5A, lanes 3 and 4). In addition, the presence of NFI was confirmed by supershift experiment using specific NFI antibodies (Fig. 5A, lane 5).

Furthermore, we performed DNase I protection assay to verify the specificity of purified NFI protein to recognize its target promoter sequence. Promoter region of human ANT2 gene spanning the nucleotides $-546 /-235$ contains two NFI binding sites (Barath et al. 1999b, 2004). As shown in Fig. 5B, binding of the recombinant NFI protein to the labeled ANT2 promoter fragment leads to specific protection (footprint pattern). Protected regions correspond to Site- 1 and Site- 2 of the ANT2 promoters which were identified during previous studies and which were shown to bind native NFI from the nuclear extracts of mammalian cells (Barath et al. 2004).

\section{Discussion}

NFI has recently been shown to act as an active repressor of two growth-regulated genes, ANT2 and p21 (Luciakova et al. 2003; Ouellet et al. 2006). We have recently shown that NFI exerts its repressor function in association with the Smad and Sp1/3 transcription factors (Luciakova et al. 2008). In order to find other proteins interacting with NFI under different growth conditions, we attempted to perform large scale proteomic studies. To do so, it was of great importance to obtain the full-length functional protein. Therefore, the aim of this work was to express and purify recombinant NFI fusion proteins that could be used for functional and structural studies. NFI has been previously isolated from mammalian nuclear extracts (Nagata et al. 1982; Gander et al. 1988; Luciakova et al. 2003). However, transcription factors purified from the native source do not contain any tags required for proteomic studies. Moreover, bacterial expression systems are faster and cheaper than any other expression systems, and suitable for purification of proteins in higher amounts. On the other hand, bacterial protein production is accompanied by disadvantages. Proteins do not form disulfide bonds, or 
perform posttranslational modifications, are often misfolded, or insoluble (for review, see Sahdev et al. 2008). High level protein expression is facilitated by the use of strong promoters, and results often in accumulation of insoluble protein aggregates in inclusion bodies (Baneyx 1992; Villaverde and Carrio 2003). Adding a tag can improve the solubility of the fusion protein. GST (Cabrita et al. 2006) or thioredoxin tag (Hammarström et al. 2002) are better than other tags (Niiranen et al. 2007) for expression of eukaryotic proteins. In addition, GST serves as affinity tag and facilitates immobilization of the fusion protein on solid support. Therefore, we have chosen combination of GST- and His-tags. His-tag is often used as it is too small to affect the structure or activity of proteins. However, addition of histidine tag may result in lower expression levels of the tagged protein compared to untagged (Gaberc-Porekar et al. 1999).

Standard IPTG-induced protein expression, even at lower temperatures did not result in production of soluble proteins. Therefore, we have changed the IPTG-induced expression to autoinduction. Induction by lactose is not immediate because the switch from glucose to lactose metabolism occurs gradually. This often leads to improved solubility of recombinant proteins (Studier 2005). On the other hand, several authors observed that autoinduction did not yield higher solubility of the target protein (Berrow et al. 2006). Similar results were observed also for NFI proteins (Fig. 1).

After optimization of the protein extraction conditions, NFI fusion proteins were first isolated under native conditions on Ni-Sepharose. However, such isolation procedure did not lead to NFI protein of high purity. Eluted fraction contained contaminating bacterial proteins, which were not eliminated by modifications of binding and elution conditions (data not shown). This was probably due to low amount of recombinant protein in bacterial lysate which allowed a prevalence of nonspecific interactions of native bacterial proteins with the resin. Prepurification of bacterial lysate on heparin column enriched the eluted protein sample (E2) in DNA binding proteins, including recombinant NFI. The following immobilized metal affinity chromatography resulted in purified NFI void of contaminating bacterial proteins. Similar procedure was applied in case of purification of overexpressed His-tagged Nef protein encoded by HIV-1 (Finzi et al. 2003).

Recombinant NFI proteins exhibit proteolytic instability (see Fig. 4C). Such instability of the target proteins fused with GST was previously reported by other authors (Rosales and Lee 2000; de Marco et al. 2004; Martínez-Torrecuadrada et al. 2005). Possible reasons for the presence of the truncated fusion proteins are GST dimerisation, the presence of an intrinsically fragile linker between the GST and the target protein, and unstable binding of the fusion mRNA to the ribosomes (de Marco et al. 2004). This instability can be eliminated by changing the GST to another fusion tag. For example, de
Marco et al. (2004) successfully used NusA instead of GST to enhance solubility and to eliminate production of truncated form. This might represent an option for future expression trials even though molecular mass of the NusA fusion with intact NFI proteins would exceed $100 \mathrm{kDa}$.

Purified recombinant NFI protein was able to recognize both consensus NFI oligonucleotide as well as specific DNA sequence within the human ANT2 promoter. This together with ability of GST-NFI to bind glutathione resin suggests that all segments of the fusion protein are folded in their native state. Therefore, this recombinant protein is suitable for protein pull-downs from mammalian nuclear extracts as it was previously reported for GST-tagged estrogen receptor (Yanagisawa et al. 2002). Identification of NFI interacting partners will clarify the role of this transcription factor in developmental pathways and might provide explanation for different functions of individual isoforms.

Acknowledgements. We thank Dr. M. Imagawa for gifts of NFI isoform cDNA vectors. This study was supported by the Slovak Science and Technology Assistance Agency (APVT) No. 26-002102 (K. L.), the Slovak Grant Agency (VEGA) No. 2/6060/26 (P. B.) and 2/0074/08 (K. L.).

\section{References}

Baneyx F. (1992): Recombinant protein expression in Escherichia coli. Curr. Opin. Biotechnol. 10, 411-421; doi:10.1016/ S0958-1669(99)00003-8

Barath P., Luciakova K., Hodny Z., Li R., Nelson B. D. (1999a): The growth-dependent expression of the adenine nucleotide translocase-2 (ANT2) gene is regulated at the level of transcription and is marker of cell proliferation. Exp. Cell Res. 248, 583-588; doi:10.1006/excr.1999.4432

Barath P., Albert-Fournier B., Luciakova K., Nelson B. D. (1999b): Characterization of a silencer element and purification of a silencer protein that negatively regulates the human adenine nucleotide translocator-2 promoter. J. Biol. Chem. 274, 3378-3384; doi:10.1074/jbc.274.6.3378

Barath P., Poliakova D., Luciakova K., Nelson B. D. (2004): Identification of NF1 as a silencer protein of the human adenine nucleotide translocase-2 gene. Eur. J. Biochem. 271, 1781-1788; doi:10.1111/j.1432-1033.2004.04090.x

Berrow N. S., Büssow K., Coutard B., Diprose J., Ekberg M., Folkers G. E., Levy N., Lieu V., Owens R. J., Peleg Y., Pinaglia C., Quevillon-Cheruel S., Salim L., Scheich C., Vincentellic R., Bussoh D. (2006): Recombinant protein expression and solubility screening in Escherichia coli: a comparative study. Acta Crystallogr. D 62, 1218-1226; doi:10.1107/ S0907444906031337

Cabrita L. D., Dai W., Bottomley S. P. (2006): A family of E. coli expression vectors for laboratory scale and high throughput soluble protein production. BMC Biotechnol. 6, 12; doi:10.1186/1472-6750-6-12 
Campbell C. E., Piper M., Plachez C., Yeh Y. T., Baizer J. S., Osinski J. M., Litwack E. D., Richards L. J., Gronostajski R. M. (2008): The transcription factor Nfix is essential for normal brain development. BMC Dev. Biol. 8, 52; doi:10.1186/1471-213X-8-52

Chaudhry A. Z., Lyons G. E., Gronostajski R. M. (1997): Expression patterns of the four nuclear factor I genes during mouse embryogenesis indicate a potential role in development. Dev. Dyn. 208, 313-325; doi:10.1002/(SICI)1097-0177(199703)208:3<313: AID-AJA3 > 3.0.CO;2-L

Cooke D. W., Lane M. D. (1999): The transcription factor nuclear factor I mediates repression of the GLUT4 promoter by insulin. J. Biol. Chem. 274, 12917-12924; doi:10.1074/ jbc.274.18.12917

de Marco V., Stier G., Blandin S., de Marco A. (2004): The solubility and stability of recombinant proteins are increased by their fusion to NusA. Biochem. Biophys. Res. Commun. 322, 766-771; doi:10.1016/j.bbrc.2004.07.189

Delgado-Olguín P., Rosas-Vargas H., Recillas-Targa F., ZentellaDehesa A., de León M. B., Cisneros B., Salamanca F., Coral-Vázquez R. (2004): NFI-C2 negatively regulates a-sarcoglycan promoter activity in $\mathrm{C} 2 \mathrm{C} 12$ myoblasts. Biochem. Biophys. Res. Commun. 319, 1032-1039; doi:10.1016/j.bbrc.2004.05.074

Deneen B., Ho R., Lukaszewicz A., Hochstim C. J., Gronostajski R. M., Anderson D. J. (2006): The transcription factor NFIA controls the onset of gliogenesis in the developing spinal cord. Neuron 52, 953-968; doi:10.1016/ j.neuron.2006.11.019

Dolce V., Scarcia P., Iacopetta D., Palmieri F. (2005): A fourth ADP/ATP carrier isoform in man: identification, bacterial expression, functional characterization and tissue distribution. FEBS Lett. 579, 633-7; doi:10.1016/ j.febslet.2004.12.034

Finzi A., Cloutier J., Cohen E. A. (2003): Two-step purification of His-tagged Nef protein in native condition using heparin and immobilized metal ion affinity chromatographies. J. Virol. Methods 111, 69-73; doi:10.1016/S01660934(03)00154-X

Fiore C., Trézéguet V., Le Saux A., Roux P., Schwimmer C., Dianoux A. C., Noel F., Lauquin G. J., Brandolin G., Vignais P. V. (1998): The mitochondrial ADP/ATP carrier: structural, physiological and pathological aspects. Biochimie 80, 137-50; doi:10.1016/S0300-9084(98)80020-5

Frangioni J. V., Neel B. G. (1993): Solubilization and purification of enzymatically active glutathione S-transferase (pGEX) fusion proteins. Anal. Biochem. 210, 179-187; doi:10.1006/abio.1993.1170

Gaberc-Porekar V., Menart V., Jevševar S., Videnšek A., Štalc A. (1999): Histidines in affinity tags and surface clusters for immobilized metal-ion affinity chromatography of trimeric tumor necrosis factor $\alpha$. J. Chromatogr. A 852, 117-128; doi:10.1016/S0021-9673(99)00374-X

Gander I., Foeckler R., Rogge L., Meisterernst M., Schneider R., Mertz R., Lottspeich F., Winnacker. E. L. (1988): Purification methods for the sequence-specific DNA-binding protein nuclear factor I (NFI) - generation of protein sequence information Biochem. Biophys. Acta 951, 411-418

Gao B., Jiang L., Kunos G. (1996): Transcriptional regulation of $\alpha(1 b)$ adrenergic receptors ( $\alpha(1 b) A R)$ by nuclear factor 1 (NF1): A decline in the concentration of NF1 correlates with the downregulation of $\alpha(1 \mathrm{~b}) \mathrm{AR}$ gene expression in regenerating liver. Mol. Cell. Biol. 16, 5997-6008

Gronostajski R. M. (2000): Roles of the NFI/CTF gene family in transcription and development. Gene 249, 31-45; doi:10.1016/S0378-1119(00)00140-2

Halestrap A. P., Brenner C. (2003): The adenine nucleotide translocase: a central component of the mitochondrial permeability transition pore and key player in cell death. Curr. Med. Chem., 10, 1507-1525; doi:10.2174/ 0929867033457278

Hammarström M., Hellgren N., van den Berg S., Berglund H., Härd T. (2002): Rapid screening for improved solubility of small human proteins produced as fusion proteins in Escherichia coli. Protein Sci. 11, 313-321; doi:10.1110/ ps.22102

Jones K., Kadonaga J., Rosenfeld P., Kelly T., Tjian R. (1987): A cellular DNA-binding protein that activates eukaryotic transcription and DNA replication. Cell 48, 79-89; doi:10.1016/0092-8674(87)90358-8

Kane R., Murtagh J., Finlay D., Marti A., Jaggi R., Blatchford D., Wilde C., Martin F. (2002): Transcription factor NFIC undergoes $\mathrm{N}$-glycosylation during early mammary gland involution. J. Biol. Chem. 277, 25893-25903; doi:10.1074/ jbc.M202469200

Luciakova K., Barath P., Poliakova D., Persson A., Nelson B. D. (2003): Repression of the human adenine nucleotide translocase-2 gene in growth-arrested human diploid cells. J. Biol. Chem. 278, 30624-30633; doi:10.1074/jbc.M303530200

Luciakova K., Kollarovic G., Barath P., Nelson B. D. (2008): Growthdependent repression of human adenine nucleotide translocator-2 (ANT2) transcription: evidence for the participation of Smad and Sp family proteins in the NF1dependent repressor complex. Biochem J. 412, 123-30; doi:10.1042/BJ20071440

Martínez-Torrecuadrada J. L., Romero S., Núñez A., Alfonso P., Sánchez-Céspedes M. Casala J. I. (2005): An efficient expression system for the production of functionally active human LKB1. J. Biotechnol. 115, 23-34; doi:10.1016/ j.jbiotec.2004.07.011

Meisterernst M., Gander I., Rogge L., Winnacker E. L. (1988): A quantitative analysis of nuclear factor I/DNA interactions. Nucleic Acids Res. 16, 4419-4435; doi:10.1093/ nar/16.10.4419

Mukhopadhyay S. S., Rosen J. M. (2007): The C-terminal domain of the nuclear factor I-B2 isoform is glycosylated and transactivates the WAP gene in the JEG-3 cells. Biochem. Biophys. Res. Commun. 358, 770-776; doi:10.1016/ j.bbrc.2007.04.185

Nagata K., Guggenheimer R. A., Enomoto T., Lichy J. H., Hurwitz J. (1982): Adenovirus DNA replication in vitro identification of a host factor that stimulates synthesis of the preterminal protein-dCMP complex. Proc. Natl. Acad. Sci. U.S.A. 79, 6438-6442; doi:10.1073/pnas.79.21.6438 
Niiranen L., Espelid S., Karlsen C. R., Mustonen M., Paulsen S. M., Heikinheimo P., Willassen N. P. (2007): Comparative expression study to increase the solubility of cold adaptedVibrio proteins in Escherichia coli. Protein Expr. Purif. 52, 210-218; doi:10.1016/ j.pep.2006.09.005

Nilsson J., Bjursell G., Kannius-Janson M. (2006): Nuclear Jak2 and transcription factor NF1-C2: a novel mechanism of prolactin signaling in mammary epithelial cells. Mol. Cell. Biol. 26, 5663-5674; doi:10.1128/MCB.02095-05

Ouellet S., Vigneault F., Lessard M., Leclerc S., Drouin R., Guérin S. L. (2006): Transcriptional regulation of the cyclindependent kinase inhibitor $1 \mathrm{~A}$ (p21) gene by NFI in proliferating human cells. Nucleic Acids Res. 34, 6472-87; doi:10.1093/nar/gkl861

Park J. C., Herr Y., Kim H. J., Gronostajski R. M., Cho M. I. J. (2007): Nfic gene disruption inhibits differentiation of odontoblasts responsible for root formation and results in formation of short and abnormal roots in mice. Periodontol. 78, 1795-802; doi:10.1902/jop.2007.060363

Robinson F. D., Moxley R. A., Jarrett H. W. (2004): Effect of the detergent Tween-20 on the DNA affinity chromatography of Gal4, C/EBPa, and lac repressor with observations on column regeneration. J. Chromatogr. A 1024, 71-78; doi:10.1016/j.chroma.2003.10.062

Rosales J. L., Lee, K. Y. (2000): Purification of dual-tagged intact recombinant proteins. Biochem. Biophys. Res. Commun. 273, 1058-1062; doi:10.1006/bbrc.2000.3063

Sadreyev R., Grishin. N. (2003): COMPASS: a tool for comparison of multiple protein alignements with assessment of statistical significance. J. Mol. Biol. 326, 317-336; doi:10.1016/ S0022-2836(02)01371-2

Sahdev S., Khattar S. K., Saini K. S. (2008): Production of active eukaryotic proteins through bacterial expression systems: a review of the existing biotechnology strategies. Mol.
Cell Biochem. 307, 249-264; doi:10.1007/s11010-0079603-6

Sawada N., Yamaguchi M. (2006): Involvement of nuclear factor $\mathrm{I}-\mathrm{A} 1$ in the regulation of regucalcin gene promoter activity in cloned normal rat kidney proximal tubular epithelial cells. Int. J. Mol. Med. 18, 665-671

Steele-Perkins G., Plachez C., Butz K. G., Yang G., Bachurski C. J., Kinsman S. L., Litwack E. D., Richards L. J., Gronostajski R. M. (2005): The transcription factor gene Nfib is essential for both lung maturation and brain development. Mol. Cell Biol. 25, 685-698; doi:10.1128/MCB.25.2.685-698.2005

Stefancsik R., Sarkar S. (2003): Relationship between the DNA binding domains of SMAD and NFI/CTF transcription factors defines a new superfamily of genes. DNA Seq. 14, 233-239; doi:10.1080/1085566031000141126

Studier F. W. (2005): Protein production by auto-induction in high-density shaking cultures. Protein Expr. Purif. 41, 207-234; doi:10.1016/j.pep.2005.01.016

Villaverde A., Carrio M. M. (2003): Protein aggregation in recombinant bacteria: biological role of inclusion bodies. Biotechnol. Lett. 25, 1385-1395; doi:10.1023/ A:1025024104862

Xiong S., Zhang L., He Q. Y. (2008): Fractionation of proteins by heparin chromatography. Methods Mol. Biol. 424, 213-221; doi:10.1007/978-1-60327-064-9_18

Yanagisawa J., Kitagawa H., Yanagida M., Wada O., Ogawa S., Nakagomi M., Oishi H., Yamamoto Y., Nagasawa H., McMahon S. B., Cole M. D., Tora L., Takahashi N., Kato S. (2002): Nuclear receptor function requires a TFTC-type histone acetyl transferase complex. Mol. Cell 9, 553-562; doi:10.1016/S1097-2765(02)00478-1

Received: February 23, 2009

Final version accepted: May 14, 2009 